DOI: https://doi.org/10.30749/2594-8261.v5n3p9-33

\title{
ANÁLISE DAS LIMITAÇÕES À LIBERDADE DE PENSAMENTO E DE EXPRESSÃO
}

\section{ANALYSIS OF LIMITATIONS ON FREEDOM OF THOUGHT AND EXPRESSION}

\section{Luatom Bezerra Adelino de Lima ${ }^{1}$}

Resumo: Este estudo analisa as condições para a limitação da liberdade de pensamento e de expressão. Propõe uma distinção em duas fases, uma interna na mente de quem pensa, vontade, pensamento, raciocínio consciente, ponderação das consequências, decisão e expressão do pensamento por qualquer meio, e outra externa após expressado, com a valoração por terceiros, seja por aceitação, rejeição ou indiferença. Metodologicamente adotou-se a pesquisa descritiva baseada na análise de alguns comportamentos humanos quando expressam seus pensamentos. Existem ainda perspectivas da liberdade de expressão pelas teorias de Justiça de Michael Walzer e John Rawls. Concluiu que tanto a liberdade de pensamento quanto a de expressão podem sofrer autolimitação, racional e conscientemente, por quem pensa. No entanto, a liberdade de pensamento não há de sofrer qualquer limitação por outrem, salvo racional e conscientemente aquiescida por quem pensa. Já a liberdade de expressão pode receber limitações contra a vontade de quem pensa desde que se observe: quais os relevantes valores devem preponderar entre quem expressa e seu potencial destinatário, e quem pode assim limitar essa liberdade. Para a primeira questão, é necessário compreender quais valores ou interesses sociais estão sendo postos em evidências. E para a segunda, confiar em última análise no Estado juiz para impor certos limites. E por se tratar de um mero ensaio, não tem a pretensão de ser completo ou exaustivo, a admitir prováveis e esperadas limitações por terceiros para futuros aprofundamentos.

Palavras-chave: Liberdade de pensamento. Liberdade de expressão. Limitações.

Abstract: This study analyzes the conditions for limiting freedom of thought and expression. It proposes a distinction in two phases, one internal in the mind of the person who thinks, will, thinking, conscious reasoning, weighing the consequences, deciding and expressing thought by any means, and another external after being expressed, with valuation by third parties, either by acceptance, rejection or indifference. Methodologically, descriptive research was adopted based on the analysis of some human behavior when expressing their thoughts. There are also perspectives on freedom of expression from the theories of Justice of Michael Walzer

1'Doutorando em Direito Constitucional pela Pontifícia Universidade Católica do Rio de Janeiro (desde de 2020). Mestre em Prestação Jurisdicional e Direitos Humanos pela Universidade Federal do Tocantins (2019). Mestre em Direito Constitucional pela Faculdade de Direito da Universidade de Lisboa (2016). 
and John Rawls. He concluded that both freedom of thought and freedom of expression can be self-limited, rationally and consciously, by those who think. However, freedom of thought must not suffer any limitation by others, unless rationally and consciously acquiesced by the thinker. Freedom of expression, on the other hand, can be limited against the will of those who think, as long as it is observed: which relevant values should prevail between those who express and their potential recipient, and who can thus limit this freedom. For the first question, it is necessary to understand which values or social interests are being put into evidence. And for the second, ultimately relying on the Judge State to impose certain limits. And because it is a mere essay, it does not claim to be complete or exhaustive, to admit probable and expected limitations by third parties for future studies.

Keywords: Freedom of thought. Freedom of expression. Limitations.

Recebido em: 31/08/2021

Aceito para publicação em: 17/11/2021 


\section{INTRODUÇÃO}

A plena liberdade é uma utopia, pois até o pensamento recebe limitações. Raciocinar é viver, fazer ilações, conexões, pontes entre construções mentais, avaliando possíveis causas, justificações e finalidades, e após aceitas as consequências forma-se uma decisão que vai alterar o mundo exterior ou o próprio corpo ou mente de quem pensa, seja num tempo infinitesimal ou após decorridos muitos anos de reflexão.

E embora do campo da neurociência, mas limitada a uma perspectiva filosófica, é possível supor que os pensamentos surjam da vontade como um desejo humano de criar infinitas imagens mentais de sua própria existência, de sua origem e destino, mundos conhecidos ou transcendentes. Autores como John Locke em 1689 e David Hume em 1739 trataram em parte a respeito, apresentando-o quanto a origem das ideias simples, complexas, formação da memória, imaginação, paixões e vontades, mas não sobre as limitações impostas após expressado o pensamento. Pensamento este que necessita ser livre, ante as infinitas possibilidades que dele decorrem como alerta Alf Ross (2007), como comer, formar a imagem mental de uma comida específica, seu provável cheiro e gosto, seja pela lembrança de uma já provada ou ainda por ser, e como consequência o raciocínio de como seria sua quantidade, textura, sabor e o custo para adquiri-la em quantidade suficiente para saciar ou apenas amenizar a fome. E quando aceitas todas suas características de acidez, amargor, salinidade e doçura, ou pelo menos suposições destas, além das possíveis limitações aos efeitos físico-químicos no corpo de quem a comerá, a conduta humana será expressada por tomar a comida e ingerir. O mesmo se dá quanto a vontade de conhecer algo abstrato como uma ideia, o pensamento criado pela imagem mental decorrente de ser boa ou má, a consequência para quem pensa ou para os outros, suas ilações com o conhecimento do antes acumulado, condições presentes e futuras, gerando ato contínuo a decisão consciente de aceitá-la ou não, reformulá-la ou até mesmo apresentá-la de forma diferente, e ainda as possíveis 
limitações que Ihe serão apresentadas por um terceiro que pode aceitá-la, rejeitá-la ou ignorá-la como desenvolvido por Kant.

Dessa mesma construção surge qualquer conduta humana, ante as infinitas possibilidades decorrentes de decisões tomadas a partir de uma vontade que parte do íntimo de cada ser pensante, e que podem acontecer milhares de vezes todos os dias durante uma vida humana, muitas sem uma aparente lembrança consciente.

Este estudo apresenta então as condições pelas quais a liberdade de pensamento e a de expressão recebem limitações, como observado por Voltaire e Rawls, partindo de uma fase interna na mente de quem pensa, passando por sua expressão e chegando ao momento em que recebe críticas de anuência, rejeição ou indiferença à ideia posta. Apresenta também as circunstâncias pelas quais são admissíveis certas limitações, e quem poderia assim limitar. Trata ainda sobre a liberdade da expressão política e sugere ao final uma visão da liberdade de expressão a partir de duas visões não coincidentes, uma pela teoria das "Esferas de Justiça" de Michael Walzer e outra por "Uma Teoria da Justiça" por John Rawls. E por se tratar de um mero ensaio sobre a liberdade, compreensível não seja completo e nem exaustivo pelo que admitirá prováveis e esperadas limitações para futuros aprofundamentos.

\section{LIMITES À LIBERDADE DE PENSAMENTO}

Das infinitas possibilidades do pensamento humano, necessário seja livre (KANT, 2016, p. 17), e só por alguém valorado após expressado. E é dessa valoração que surgem as limitações, pela aceitação ou rejeição da proposta dada, ou sua indiferença, num contínuo processo cíclico de formação do pensamento humano (vontade, pensamento, raciocínio consciente, ponderação das consequências, decisão, expressão e valoração por terceiros por aceitação, rejeição ou indiferença). Vai então do pensamento como uma ideia substantiva até se concretizar como um verbo de conduta. 
E embora nem toda conduta humana decorra de um raciocínio consciente, por se constatar comportamentos reflexos a estímulos dos sentidos, como a fuga da dor (HUME, 2009, p. 28 e 450), a aversão a sabores, o incômodo luminoso, a repulsa a certos níveis sonoros ou a odores pútridos, e ainda os praticados por instintos e impulsos voltados à sobrevivência, como o sugar e o se agarrar para os recém-nascidos, respirar, fugir ou enfrentar um golpe inesperado como um movimento de defesa, para todos os humanos. Também há condutas influenciadas por causas internas humanas, como as decorrentes da sanidade física e mental de quem pensa (doenças do corpo ou da mente), ou por ausência ou incompleto conhecimento técnico, científico, filosófico ou religioso suficiente à compreensão do que se apresenta, como no analfabetismo (ausência do letramento básico) ou a falta de completa compreensão dos altos estudos. E ainda há a influência por causas externas naturais, como as decorrentes da força da natureza (temperatura, pressão, clima, movimento planetário, frio, calor, água, animais, plantas) (LOCKE, 1997a, p. 107), que diminuem ou excluem a lucidez e a serenidade de uma decisão, e por ação humana. Sejam as causas internas ou externas, todas podem influenciar a total ou parcial compreensão de um fato, por um curto período de tempo ou por toda uma vida, e com isso a liberdade de expressão. No entanto, de interesse para este estudo apenas as condutas humanas raciocinadas que imponham limites tanto à liberdade de pensamento quanto a de expressão, ante a necessidade de a razão estar sempre condicionada a crítica como advertido por KANT (KANT, 2015, p. 546).

E quanto a essas limitações, mostra-se sem dúvida admissível a limitação da liberdade de pensamento quando aquiescida racional e conscientemente (LOCKE, 1997b, p. 929; KANT, 2015, p. 531; VOLTAIRE, 2012, p. 351; PAINE, 2005, p. 124), e haja relação direta com um benefício esperado, mesmo não alcançado. Assim, se poderia supor os seguintes condicionantes: um benefício esperado, mesmo que não alcançado; uma limitação aceitável; guardar relação direta entre o benefício esperado e a limitação aceitável; aceitação racional e consciente; e ser o beneficiário o próprio que sofra a limitação ou terceiro por este indicado. Decorrente então desta análise, alguém querer (aceitação racional e consciente) se submeter a 
um transplante de rim (benefício esperado, mesmo que não alcançado) em favor de um parente (beneficiário um terceiro por aquele indicado), no qual a anestesia geral é uma condição indispensável sem a qual é impossível remover o rim doado (guarda relação direta entre o benefício esperado e a limitação aceitável), a pessoa perde completamente a capacidade de raciocínio durante o tempo do ato cirúrgico (limitação aceitável), porém espera a melhora do quadro de saúde do transplantado (benefício esperado, mesmo que não alçado). Por uma outra análise, quando alguém (beneficiário o próprio) aceita se submeter (aceitação racional e consciente) a um bom trabalho em zona rural onde irá receber melhores salários (benefício esperado, mesmo que não alçado), oferecido em condições que o impede de acesso a conhecimentos técnicos, científicos, filosóficos ou religiosos (limitação aceitável), por guardar relação direta entre o benefício esperado e a limitação aceitável, não se estará diante de uma limitação desarrazoada. Outra possibilidade, alguém aluga (aceitação racional e consciente) apenas um cômodo de imóvel maior (benefício esperado, mesmo que não alcançado) para nele morar com sua família (beneficiário o próprio que sofre a limitação ou terceiro por este indicado) ciente de que o locador que também lá reside é muito barulhento (limitação aceitável), em razão do preço e da localização do imóvel (guardar relação direta entre o benefício esperado e a limitação aceitável). Por outro lado, afeiçoa-se desarrazoada, ou seja, não poderá ser limitado o pensamento, na hipótese de um paciente (beneficiário o próprio que sofre a limitação), que mesmo aquiescendo (aceitação racional e consciente) num tratamento experimental de saúde contra um vírus (benefício esperado, mesmo que não alcançado) tenha como efeito colateral uma permanente incapacidade mental (limitação inaceitável), por não guardar relação direta entre o benefício esperado e a limitação intolerável. Também não será possível limitar o pensamento de um aluno, que mesmo matriculado no curso de sua preferência (beneficiário o próprio), e ciente de seu cronograma (aceitação racional e consciente), e almejando apenas concluí-lo no tempo estipulado pelo programa (benefício esperado, mesmo que não alcançado), é obrigado a estudar apenas por autores que não se oponham ao 
posicionamento ideológico do professor (limitação inaceitável), por não guardar relação direta entre o benefício esperado e a limitação inaceitável.

Já quanto a possibilidade de alguém conscientemente aceitar se submeter a um tratamento de tortura visando um relevante benefício qualquer por ele esperado, deve-se considerar o nível de tolerância à limitação imposta, pois se suportável não seria tortura, e sendo insuportável pelo intenso sofrimento físico ou mental, já não haveria aceitação racional e consciente, e com isso inadmissível a hipótese. Por outro ângulo, a submissão de alguém a uma limitação da liberdade de pensamento por ação de outrem quando assim não aquiesceu não se mostra aceitável por inexistir anuência, mesmo que tolerada, impedindo o natural e contínuo fluxo do processo cíclico da tomada de decisão (vontade, pensamento, raciocínio, ponderação das consequências e decisão). Inclusive neste ponto relevante observar que algumas limitações podem ser impostas não só individualmente, mas também coletivamente, como a havido na sociedade soviética à época de Stálin ante a propaganda estatal que falseava, ocultava e apagava fatos ou criava novos, pois tudo era vigiado e denunciado (ARENDT, 2012, p. 428; COURTOIS et al, 2019, p. 442).

Dessas premissas, inadmissível então haja uma limitação da liberdade de pensamento por conduta humana de terceiro quando não aquiescida, por indicar um constrangimento, uma importunação, uma coação, uma violência ou até uma tortura, aniquilando a principal distinção humana dos animais. A liberdade de pensamento só deve estar sujeita a autolimitação, e apenas durante o processo de formação da razão, nunca por ação humana externa não aquiescida. O pensamento deve vagar livre, mesmo que dissociativo, maldoso, belicoso, racista, criminoso e anti social, pois até o último instante antes de expressado pode sofrer uma autolimitação por freio moral, religioso, filosófico ou legal e até transformar-se em seu oposto, algo bom, sublime, ético, moral ou justo. A razão analisará as consequências positivas e negativas idealizadas, de acordo com a compreensão de quem pensa. E mesmo quando essa limitação for expressa ou tacitamente anuída, não significa esteja sujeita a qualquer limitação. A liberdade de pensamento se sobressai portanto como 
uma especial, valiosa, absoluta, irrenunciável, indisponível e indispensável condição humana que não deve sofrer qualquer limitação por outrem contra a vontade expressa ou tácita de quem pensa.

\section{LIMITES À LIBERDADE DE EXPRESSÃO}

Já quanto à limitação da liberdade de expressão não aquiescida, deve-se condicioná-la a impedir um mal maior a ser praticado por quem a expressa ou a terceiros, uma vez que nada atingindo interesses de terceiros, que sabem ou podem se defender, afeiçoa-se irrelevante para os demais o que cada um faça de sua vida. Deste modo, o fato de alguém optar por certa preferência política, religiosa ou sexual, e não trazendo com isso qualquer prejuízo à autonomia racional e consciente da vontade de outrem, não há que sofrer qualquer limitação nem mesmo pelo Estado. No entanto, será necessária a limitação quando possa atingir relevantes valores de terceiros. Aqui é onde se situam as maiores dificuldades analíticas, sendo a primeira, quais valores devem preponderar e a ponderação dos interesses de quem expressa, e seu potencial destinatário, e a segunda, quem deva ser o censor, aquele que irá impedir ou desfazer a ofensa praticada, partindo do pressuposto de que não há plena liberdade de expressão do pensamento, sob pena de autoritarismo.

Não promover ou incentivar valores éticos, morais, filosóficos, religiosos ou jurídicos é enfraquecer a autolimitação do pensamento, e com isso permitir expressões de pensamentos dissociativas, beligerantes e egoístas. Não valorizar a ética é diminuir os vínculos de lealdade no ambiente profissional, e com isso a vitória do bajulador ou do plagiador de ideias. Não alimentar valores morais como a cooperação nas tarefas domésticas ou a correção dos maus pendores das crianças (LOCKE, 1997a, p. 74) é promover o individualismo, o desvalor do trabalho e com isso a apatia aos sofrimentos sociais, pois é na infância e juventude (MALVESTIO, 2015; ZIMMERMANN; TORRIANI-PASIN, 2011, p. 731) que se aprende valores que irão constituir a futura personalidade, sem os quais a pessoa ficará suscetível aos 
maus pendores. Decorrente disso, induzir ou incentivar o consumo de drogas é fomentar a diminuição da reflexão racional e com isso a autolimitação moral que por sua vez impede a compreensão exata das complexas relações sociais, retirando a autoridade crítica quanto a outros comportamentos antissociais como a corrupção. Menosprezar o valor da fé, como submissão a uma vontade criadora abstrata que tudo vê, explica e controla, é dá vazão a impulsos instintivos e violentos (ARISTÓTELES. 2001, p. 95), sobretudo quando bilhões de pessoas em todo o mundo acreditam em algo transcendental, um deus criador. Enfraquecer também a força da norma jurídica como produto da razão dos representantes de uma maioria (PLATÃO, 2010, p. 25), com interpretações criativas ou mais flexíveis em favor de certos privilegiados, é alimentar a lei do mais forte, do mais influente, do mais corrupto (MILL, 2019, p. 15). Inclusive neste aspecto os Estados Unidos vivenciaram essa sensação após se tornarem independentes do Império Inglesa, quando não dispunham de qualquer arcabouço jurídico como registrado por Paine (PAINE, 2005, p. 83).

E ainda: o que impede um homem de atacar uma jovem estudante desarmada que volta para casa à noite numa rua deserta e mal iluminada, onde não há testemunhas e nem câmeras de vigilância senão as autolimitações do pensamento dele decorrentes da ética, da moral, da filosofia, da religião e do Direito? O que impede um servidor público, chefe de repartição ou até mesmo um Presidente da República, de ser desonesto, quando ele mesmo é o responsável pela segurança e vigilância do patrimônio do povo atacado, senão aqueles mesmos valores que possa ter acumulado durante sua formação? A corrupção ética, moral e criminosa decorre da ausência ou banalização das autolimitações à liberdade de expressão, ou ainda do buscar justificações falsas que as calam ou escamoteiam.

Lembrar que liberdade de expressão não significa apenas a reconhecida em favor da fala, da escrita ou de se ter opinião (HEGEL, 1997, p. 288) ou crença, mas de toda conduta humana racional exteriorizada, por decorrer do pensamento, como já demonstrado. No entanto, a liberdade de expressão pode, e em muitas situações deve, receber limitações de terceiros, independentemente da anuência do agente, 
pois onde houver duas ou mais pessoas haverá possivelmente uma interferência limitativa àquela liberdade, ante a possibilidade de o exercício do pensamento de um importar no aniquilamento do outro.

Se o pensamento deve ser livre, e só se sujeitar a autolimitação, e a liberdade de expressão só deva sofrer limitação para impedir um mal maior a ser praticado por quem o expressa ou a terceiros, necessário primeiro que quem expressa e seu destinatário mantenham sintonia no meio utilizado (MARÍAS, 2015, p. 91; HABERMAS, 2020 , p. 44). Se o meio for a fala ou a escrita, como exemplos, embora existam uma infinidade de outros meios, como as artes, a música, a dança, o teatro, deve-se compreender não só o idioma e suas regras (LOCKE, 1997b, p. 545 e 719), como também os postulados morais, filosóficos, jurídicos ou científicos utilizados, sua razão e consequências da decisão expressada. Perdida essa sintonia, entre quem expressa seu pensamento e seu destinatário nada ou pouco é compreendido, havendo interpretações ou limitações descabidas ou desarrazoadas do pensamento posto. A expressão será tida como não verdadeira, pois de fato não será para quem não compreende como esta se formou. A verdade é portanto a conformação a uma expressão do pensamento contra o qual não se pôde apresentar limitações (LOCKE, 1997b, p. 725 e 791). Sua falta, seja pela incompreensão do meio empregado, bloqueio preconceituoso dos pensamentos apresentados, recusa deliberada em compreendê-los, ou apenas uma simulação desta sintonia com um movimento de se aguardar a vez de revidá-la, não se mostram adequados como limitações à liberdade de expressão. Necessário que o emitente esteja ciente da vontade, da razão e das consequências dessa expressão, para só então poder restringir o tempo, o modo, o meio, os destinatários e seu alcance. A dificuldade está em encontrar meios de se limitar a liberdade de expressão contra a vontade de quem a expressa, quando suas consequências não são as queridas ou esperadas pelo destinatário, pois nem sempre o pensamento posto guarda sintonia com a vontade idealizada, sua razão, consequências, ou entre esta e a recusa do destinatário. 
Do caminho cíclico entre a vontade, pensamento, raciocínio consciente, ponderação das consequências, decisão, expressão do pensamento e valoração por terceiros com aceitação ou rejeição do expressado, fica neste último momento o ponto de maior debate, pois enquanto na fase interna não se deve haver limitações por terceiros não aquiescidas, expressado é necessário que a limitação imposta guarde sintonia com a proposta dada. Caso o destinatário tenha plena consciência das consequências do que the foi apresentado, não havendo causas internas ou externas outras que interfiram em sua avaliação, e ainda só interfira em sua liberdade de igualmente assim expressar, a participação de outros será desnecessária. Porém, quando as consequências forem sentidas por uma coletividade que não pode direta ou indiretamente expressar sua aquiescência ou rejeição, é indispensável encontrar um meio de se permitir limitações, assim como deixar claro quem pode ou deve limitar a expressão do pensamento de outrem.

\section{QUEM PODE LIMITAR A LIBERDADE DE EXPRESSÃO}

De logo, deve-se considerar seja o destinatário ou a pessoa que sofre ou pode sofrer as consequências do pensamento por outrem expressado como o legitimado para assim apresentar suas limitações, quando entender não haver razoabilidade na crítica recebida, indo até mesmo ao Estado juiz buscar maior proteção para impedir sua continuidade (HUME, 2009, p. 589). No entanto, há outros partícipes dessa relação pensamento expressado e seu destinatário, como os tradicionais meios de comunicação (editora de livros, jornais, rádio e TV) e os novos disponíveis na rede mundial de computadores (YouTube, Twitter, Instagram e Facebook), quando impedem publicações de autores ou textos, não divulgam deliberadamente certas notícias, bloqueiam usuários, limitam ou impedem suas postagens. Torna-se então relevante a análise da pertinência da censura ou limitação apresentada por esses meios de comunicação ante a forte influência que gera na opinião pública e a modificação dos costumes (TOCQUEVILLE, 2019, p. 243). Aqui tem-se os editores de livros, chefes de redação dos jornais e funcionários 
de empresas privadas de redes sociais mundiais, estranhos portanto a ideia livremente expressada e seu destinatário, os quais se põe semelhantes à juízes decidindo o que é ou não ofensivo, ético, moral, odioso ou criminoso (HUME, 2009, p. 593; LOCKE, 1997a, p. 57), sempre se justificando no cumprimento de uma relação contratual particular entre quem disponibiliza o meio e seus usuários (HIRSCHL, 2020, p. 354; WEINREB, 2008, p. 126). Mas, será admissível que o meio de comunicação assim possa limitar a liberdade de alguém quando expressa seu pensamento num texto, numa imagem, numa arte, numa notícia tão somente por supostamente estar defendendo interesses maiores de outros? E olhando sobre a outra perspectiva, seria os meios de comunicação uma terra sem lei, onde tudo pode, até mesmo propagandas nazistas, stalinistas, racistas ou anti nacionalistas? Se admissível a censura, até onde iria sem ferir a liberdade de expressão? Se não, deveria ficar absolutamente neutro o meio de comunicação frente a qualquer agressão até mesmo contra quem não sabe ou não pode se defender, ou até sequer sabe que está sendo atacado? E ainda, e quando a limitação decorrer de conduta do próprio Estado, seja por comportamentos antiéticos, imorais, odiosos, desrespeitosas quanto à fé alheia, ou de censura inconstitucional, sendo ele o único detentor do monopólio do uso da força de exercer em nome de outrem o poder de impedir a continuação de uma expressão do pensamento com conteúdo ofensivo, cuja legitimação decorreria da formação política da vontade da maioria expressada por leis aprovadas pelos representantes da maioria? Quem poderia censurar o próprio Estado? (BURKE, 2017, p. 34; WEBER, 2015, p. 62)

De logo, se afeiçoa perigoso permitir que terceiros, não autorizados pelo Estado, adotem comportamentos judiciais estatais de monopolizar a análise do que seja ético, moral, filosófico, científico ou jurídico, por demandar interpretação própria e particular em possível oposição aos interesses de outrem, além do risco de enviesar o discurso num único sentido, expressando quase sempre um autoritarismo e não conduta democrática, impedindo com isso a alternância e a crítica das ideias. Logo, jornais e redes sociais quando impedem seus leitores e usuários de conhecerem todas as versões de uma mesma história assumem comportamentos de 
censores antidemocráticos, sendo exatamente o oposto do que querem parecer defender (HUME, 2009, p. 20). E não há dúvida que o discurso de ódio ou criminoso deva ser sim sempre rechaçado, mas preferencialmente pelo próprio interessado, mediante a disponibilização de ferramentas ofertadas pelos meios de comunicação (como uma errata, o direito de resposta (LEITE, 2018) ou os bloqueios eletrônicos pelo próprio destinatário de não mais receberem certas postagens), e quando não suficientes para obstar a ofensa, comunicar ao Estado para análise por meio das várias entidades como órgãos de defesa do consumidor, Defensoria Pública, Ministério Público, Poder Legislativo e o Poder Judiciário, os quais assim exercem autoridade por vontade da maioria do povo que os legitimou constitucionalmente. No entanto, quando o comportamento limitativo e censor decorrer do próprio Estado resta inicialmente a utilização dos mesmos instrumentos de defesa fornecidos pelo Estado, e quando estes coactos, impedidos ou até participem dessas limitações desarrazoadas só restaria aguardar o término dos respectivos mandatos eletivos ou por uma resistência civil (DWORKIN, 2019, p. 156) não violenta, já que a submissão de todos à autoridade do Estado parte do pressuposto de que a existência deste serve para proporcionar segurança aos que a ele estão submetidos (HUME, 2009, p. 591).

\section{A LIBERDADE DA EXPRESSÃO POLÍTICA}

E ainda quanto às limitações à liberdade de expressão, necessário não se perca a distinção entre a liberdade de expressão da vontade política em relação ao Estado (RAWLS, 1996, p. 318), quanto ao modo de ser por este tratado, e a liberdade de expressão da vontade individual, em relação às demais pessoas, quando expressar um sentimento próprio ou de outrem, de um sentimento religioso ou filosófico, de se relacionar com o outro individual ou coletivamente, de querer ir e 
vir, de como se instruir, seja por educação formal ou por informação direta ou ainda acumulação de patrimônio, embora a política não se limite à atividade partidária por interesses estatutários, mas como toda opção humana por um modo de desempenhar sua vontade ou diretriz (WEBER, 2015, p. 61). Na relação pública espera-se prepondere o mais próximo possível um tratamento de igualdade que o Estado disponibilize para todos, e quando assim impossível pelas múltiplas condições, características individuais ou interesses, que se garanta ao menos ao mais frágil poder expressar seu pensamento, o que não significa garantia de que será admitido ou acatado, devendo ficar ciente da necessidade de submissão à vontade da maioria (DWORKIN, 2019b, p. 562), quando vencido, em razão de suas ideias poderem já terem sido antes testadas e geraram dissociação social, crimes ou instabilidades políticas, ou ainda não estejam prontas para serem implementadas.

É certo que sendo a resistência civil a última ou única opção, necessário não seja violenta, mas organizada e contínua, pois assim desempenhará forte pressão política por se assemelhar a uma avalanche de vontades num único sentido, retirando a legitimidade das condutas políticas de então. Mas quando violenta e criminosa a enfraquece e a deslegitima, por indicar um autoritarismo contra o qual supostamente se luta. Garantir lugar de fala (RIBEIRO, 2017), voz direta nas ruas, representação política (MILL, 2020, p. 59) ou positivação de direitos significa pouco, se não houver uma forte adesão de uma maioria formada não só pelos atingidos das restrições impostas, mas também de outras classes ou grupos, que movidos por um sentimento de empatia (SMITH, 2015, p. 5), benevolência (KANT, 2013, p. 265), pertencimento (SCRUTON, 2019, p. 11), nacionalismo, união por vontades parcialmente comuns, de não sujeição ao pensamento de um grupo que quer parecer falar por todos, que acredita ter uma visão privilegiada do futuro, o dom divino da onisciência, que obviamente nenhuma sociedade até hoje teve, não permitirão que excessos sejam assim cometidos. É dessa união por conjugação de interesses comuns em sentido mais amplo, sejam políticos, filosóficos, morais, científicos, econômicos ou sociais, de lutar em favor de um objetivo comum, mesmo que não levantem as mesmas e exatas bandeiras, que pode haver resultados mais 
significativos. Conquistar a maioria deveria ser a meta, e não a minoria lutar contra a maioria já formada. Quem busca promover apenas minorias sem formação de uma nova maioria na verdade promove discurso demagógico (LOCKE, 1997b, p. 918), ou hipócrita no dizer de Kant (KANT, 2015, p. 552), de querer parecer bom, sensível, que enxerga os oprimidos e lhes dá voz, além de alimentar lutas fratricidas (SMITH, 2015, p. 426) em vez de convencê-la dos pontos em comum, trazê-los para serem seus defensores (VOLTAIRE, 2019, p. 15).

Quando na Constituição Americana de 17 de setembro de 1787 ficou expresso por eloquente omissão o não reconhecimento aos negros de direitos civis igualmente conferidos aos brancos, impondo com isso uma segregação racial por quase um século; quando na Constituição Russa de 17 de janeiro de 1918 foram confiscadas todas as propriedades privadas, de ricos e pobres, como ideário comunista utópico de igualdade, levando miséria e fome ao povo soviético nos anos que se seguiram; e quando pelas Leis de Nuremberg expedidas por Adolf Hitler em 15 de setembro de 1935, aprovadas por seu Parlamento, que tratavam da Proteção do Sangue e da Honra Alemã e da Lei de Cidadania do Reich, impondo fortes restrições às liberdades dos judeus, os empurrando para a morte coletiva em poucos anos, as liberdades dessas milhões de pessoas negras, russas e judias foram restringidas sem que Ihes fossem sequer oportunizados voz direta nas ruas ou indireta nos parlamentos para assim se contraporem, em evidente movimento de indevida restrição à tais liberdades. No entanto, supondo fossem consultados, cada um em sua época, seja diretamente toda a população negra escravizada americana em 1787, a russa em 1918 e a judia alemã em 1935, casa por casa, pessoa por pessoa, concedendo-lhe voz e lugar de fala, suas esperadas oposições às limitações dessas liberdades seriam consideradas? E esse tão somente falar iria garantir alguma efetiva mudança? Haveria possibilidade de a sociedade americana de então, que acabara de vencer o poderoso Império Inglês, ouvir a minoria negra ainda escravizada e a eles conceder os mesmos direitos civis que se concedia ao novo povo branco vitorioso? Haveria a possibilidade de os bolcheviques recuarem na tomada das propriedades privadas sem o risco de parecerem trair o movimento 
revolucionário e manter o mesmo regime imperial dos czares que tanto desprezavam? Ou ainda, alguma chance de o Partido Nazista Alemão não considerar os judeus como os culpados por toda uma trajetória histórica de fracasso daquele povo entre o fim do Século XIX e início do Século XX, os mantendo ainda influentes nas tomadas de decisões políticas? As respostas óbvias para cada uma dessas questões é não. Não, porque não foi apenas a voz dos negros que encerrou a escravidão americana (MISES, 2010, p. 51), mas a adesão consciente de uma parcela significativa de uma maioria branca, inclusive do Presidente da República de então, Abraham Lincoln, um homem branco do Partido Republicado que liderou o movimento pelo fim da escravidão, pagando com a própria vida o alto preço de expressar livremente seu pensamento quando juntou força com negros e venceram aquele período odioso de sua história. Também não foi apenas a resistência do povo judeu que impôs fim ao nazismo, mas a adesão consciente de dezenas de outros povos, milhões de pessoas de diferentes países, culturas e religiões não judaicas, inclusive brasileiros, que venceram Hitler e as forças do eixo. Também não foram apenas a resistência dos proprietários de terras que fizeram desmoronar o comunismo de Stalin, mas a existência de sociedades capitalistas no entorno demonstrando ano após ano a fragilidade da pseudo igualdade econômica na distribuição de riquezas, com o crescimento e evolução das sociedades baseados no mérito decorrentes do suor do próprio esforço.

São os sentimentos decorrentes do nacionalismo (HAZONY, 2019, p. 13), patriotismo, conservadorismo que valoriza as caras conquistas do passado (SCRUTON, 2019, p. 111), como a ética, a moral, a religião, a defesa das liberdades civis, o pluralismo cultural, a busca por redução das desigualdades que podem gerar pontos de interseções por interesses comuns. Até porque criticar o conservadorismo como algo que remota a ideias imutáveis, protecionistas e de manutenção de privilégios é um tanto preconceituoso, pois os defensores de maiores liberdades civis, com bandeiras revolucionárias morais também querem conservar e ampliar liberdades que entendem justas, conservando-as quando já os exercem como uniões civis entre pessoas do mesmo sexo, liberação do uso de drogas, legalização 
do aborto. No entanto é a valorização dos campos comuns que trará mais adeptos pela segurança que proporcionará, fazendo com que haja migração dos que estejam em campos isolados, os ultrarradicais. Nesses pontos de interseções não só há negros, russos e judeus mas também religiosos que não aceitam a submissão de pessoas negras à força de brancos, por entenderem não ser assim bem visto aos olhos divinos, além de os filósofos libertários não verem lógica ética no extermínio de pessoas judias tão somente por assim se declararem, e nem empresários capitalistas, que fomentavam empregos e desenvolvimentos sociais de sociedades europeias aceiterem os comunistas russos dividirem suas classes sem qualquer crescimento ou benefício daí decorrente ao povo soviético.

\section{A LIBERDADE DE EXPRESSÃO COMO IDEAL DE JUSTIÇA}

Partindo agora para uma visão específica de justiça sob a ótica de Michael Walzer, quando propõe em "As Esferas da Justiça" (WALZER, 1999, p. 28) que cada um só se beneficie dos valores que possa legitimamente alcançar e desde que auxiliado pelo Estado, se for considerado uma minoria, onde o bem social de uma esfera não pode trazer benefícios às esferas anexas, espera-se aqui exatamente o oposto, pontos de união entre interesses comuns podem trazer melhorias desde que garantida a liberdade de expressão em favor de todos. Ser rico, ou detentor do bem social de maior interesse nas sociedades capitalistas, pode trazer melhorias ou vantagens educacionais, não pela existência da riqueza, mas pelo progresso que ela proporciona. No entanto, o autor desconsidera que em universidades custeadas por ricos, as vultosas doações pela participação de filhos de ricos que lá ingressarem por méritos educacionais próprios, sem corrupção ou fraude, podem trazer melhorias para todo o mundo, como ocorreu com a Universidade de Harvard, de Chicago e de Princeton, onde lá também estudam pobres, beneficiários de bolsas de estudos, ou por incentivos de crédito governamental, embora Sandel critique esse modelo como tirania do mérito pelos privilégios hereditários das grandes fortunas (SANDEL, 2020, p. 169). Mas foram nelas que grandes avanços sociais ocorreram. Quando Milton 
Friedman recebeu em 1976 o prêmio Nobel de Economia do Banco Central da Suécia e em 1988 a Medalha Presidencial da Liberdade do governo dos Estados Unidos, não foi ele assim honrado por sua origem privilegiada, mas tão somente por sua contribuição na análise econômica do livre mercado e intervenção mínima na economia (FRIEDMAN, 2020), embora fosse na verdade filho de imigrantes judeus nascido em 1912 numa região pobre dos EUA, Brooklyn, estudando com bolsa na Universidade de Chicago. E quando William Arthur Lewis foi agraciado em 1963 com o título de Cavaleiro de Sua Majestade e em 1979 com o Prêmio Nobel de Economia por sua contribuição na análise econômica de países em desenvolvimento (RANIS, 2004) também não se observou ser ele um negro pobre nascido no Caribe em 1915, filho de imigrantes africanos, estudando com bolsa na Escola de Economia e Ciência Política de Londres. Ambos, Friedman e Lewis, integraram grupos minoritários (judeu e negro), estudaram em prestigiadas universidades custeadas por vultosas doações de outros grupos sociais majoritários, nacionais brancos e ricos, sem que se argumentasse desarrazoabilidade ou privilégios nessas doações e nem que lá ascenderam por méritos próprios (XAVIER, 2019, p. 103). Desconsiderar a expressão do pensamento de ambos tão somente porque um é judeu e o outro negro soa dissociativo, preconceituoso e não traz qualquer progresso social, assim como considerar seus escritos tão somente por serem judeu e negro igualmente não valoriza suas ideias e propostas, mas induz uma condescendência bajulativa e hipócrata.

Já analisando a liberdade como ideal de justiça pela proposta de Rawls, para o qual uma boa justiça libertária necessário atenda uma razão pública na tomada de decisões (RAWLS, 1996, p. 229), semelhante a uma síntese de julgamento da mais alta corte de justiça contra quem expressou o pensamento, porém isenta de suas próprias preferências morais, religiosas, filosóficas ou científicas, mesmo que não haja unanimidade nas decisões. Embora na perspectiva de Amartya Sen (SEN, 2011, p. 351) não seja possível olhar a liberdade apenas sob uma única perspectiva, há de se considerar tanto a intenção de quem expressa o pensamento, como também de quem é seu destinatário. Para Dworkin (2019b), a 
liberdade de pensamento é a garantia de uma sociedade politicamente justa, uma autonomia moral do cidadão em gerir sua própria vida, sem receio de indenizar outrem apenas por dizer o que pensa, e não necessariamente porque assim pode surgir algo de bom do que possa ser dito (DWORKIN, 2019b, p. 318, 319 e 326). E na perspectiva de Sandel, que inicia citando o conto de "Aqueles que se afastam de Omelas" de Úrsula Guin (SANDEL, 2012, p. 135 e 321), no qual a autora de ficção científica descreve uma harmoniosa, feliz e próspera cidade de Omelas, onde todos vivem livres e em paz, porém garantidos pelo cárcere num subsolo de uma criança mal nutrida, doente, e aprisionada, da qual todos têm conhecimento e expressamente assim a mantém para o bem comum, encontrando sempre múltiplas justificações para lá mantê-la e não quebrar o equilíbrio encontrado, concentrando Sandel na abordagem de uma justiça pela perspectiva de Kant, justiça decorrente da moral e da valorização da liberdade, com a qual não concorda por privilegiar certos direitos em detrimentos de outros, numa escolha quase sempre não racional, mas induzida. Defende uma justiça baseada na aceitação das divergências em prol de um bem comum para formar uma sociedade justa com forte sentimento de comunidade (SANDEL, 2012, p. 325), porém limitando-se a apresentar sintética crítica à formação das riquezas, mas sem apresentar uma teoria objetiva de como atingir essa sociedade justa.

A partir dessas perspectivas, um ideário de justiça no exercício da liberdade de expressão só se admite com o contraditório de ideias, pois a liberdade de fala compreende também a de saber ouvir e respeitar a decisão da maioria, pelo silogismo lógico de que uma maior quantidade de pessoas se submeterá à vontade posta. Fora desses parâmetros é autoritarismo de Estado (MAQUIAVEL, 2010, p. 79), ou tentativa de opressão vinda de minorias (BOBBIO, 2015, p. 370). A relação precisa ser bilateral. Impedir a expressão do pensamento alheio por suposta proteção de outras minorias soa apenas como mais um modo autoritário e melífluo de opressão. Já no âmbito das relações entre particulares também nem sempre é possível uma igualdade plena, ante a possibilidade de haver algum poder de um sobre o outro, sejam por razões familiares, sociais, econômicas ou religiosas, mas 
em última análise cabe ao Estado dirimir tais conflitos (HABERMAS, 2018, p. 402 e 405).

\section{CONSIDERAÇÕES FINAIS}

Em síntese, a liberdade plena é uma utopia, seja a de pensamento ou a de expressão, pois ambas podem receber em algum momento limitações que as impedem de continuamente se formar e alterar o mundo ao redor de quem pensa. Já a formação do pensamento humano pressupõe uma construção mental partindo da vontade, que faz surgir um raciocínio consciente, levando a ponderação das consequências da decisão a ser tomada, e quando expressada passará por alguma valoração por terceiros, seja pela aceitação, rejeição ou indiferença. Há causas internas e externas que limitam o pensamento humano, sendo admissíveis quando aquiescidas, e inadmissíveis, embora possíveis, quando não concordes com a vontade de quem apenas pensa.

O pensamento precisa então ser livre, enquanto não expressado, por ser uma garantia básica do existir humano, não se restringindo a expressão da fala, escrita ou opinião, mas toda conduta humana racional. E quando admitida a limitação do pensamento pelo próprio pensador necessário atenda a alguns condicionantes: haja um benefício esperado, mesmo que não alcançado; se preveja uma limitação aceitável; guarde relação direta entre o benefício esperado e a limitação aceitável; decorra de uma aceitação racional e consciente; e seja o beneficiário dessa limitação o próprio pensador ou terceiro por este indicado. Já as limitações impostas contra a vontade de quem expressa o pensamento, em algumas situações são admitidas, pois nem sempre se produz algo harmonioso ou que traga algum progresso para quem pensa ou a terceiros. Devendo ser bem analisado quem pode ou deve limitar as expressões do pensamento de terceiros quando abusivos.

Tanto a liberdade de pensamento quanto a de expressão podem sofrer autolimitação, racional e conscientemente, por quem pensa, isso é incontroverso. A 
dificuldade se apresenta quando necessário limitar a liberdade de expressão contra a vontade racional e consciente de quem pensa, pela intuitiva e óbvia suposição de que nem tudo o que é expressado pelo pensamento humano pode ser perfeito, sem falhas. Há condutas que precisam ser limitadas porque dissociativas, beligerantes, criminosas ou ofensivas. Deve-se portanto limitá-la a impedir um mal maior a ser praticado contra quem a expressa ou contra relevantes valores de terceiros, que igualmente também tem liberdade de pensar e de se expressar. As duas maiores dificuldades são, portanto: quais os relevantes valores devem preponderar entre quem expressa e seu potencial destinatário e quem pode assim limitar a liberdade de pensamento de outrem, quando não aquiescido racional e voluntariamente. Para a primeira questão, é necessário compreender quais valores ou interesses sociais estão sendo postos em evidências. Há de se indagar, valoriza-se a ética, a moral, razões filosóficas, religiosas ou jurídicas que trazem ou mantêm o equilíbrio social e a constante e contínua liberdade de pensamento e de expressão de todos? Há sobreposição de interesses essencialmente conflituosos? Se sim, é necessário um agir poderoso para arrefece-los e manter a equidade nas relações sociais. Admitir que pela força ou pela corrupção se domine outrem ou uma coletividade, não favorece a valorização da liberdade de todos. Admitir que se utilize de sua peculiar visão de mundo, falível, já antes testada e que traz mais instabilidades que ganhos, não pode preponderar apenas por advir de alguém que detenha poder político ou econômico ou se auto afirme em circunstância minoritária historicamente e perseguida, é necessário se manter um contínuo diálogo e saber ouvir e respeitar a decisão majoritária, partindo para o convencimento pelos pontos em comum, e não à força pelas dissensões. Já para a segunda questão, quem pode deter o poder de assim limitar a liberdade de expressão quando não aquiescida, deve-se confiar na força do Estado, no juiz, transferir para este a capacidade da tomada dessa decisão, a qual se compreender aqueles valores em disputa, os interesses envolvidos, e buscar esse equilíbrio social, haverá harmonia nas relações. Faltando a imparcialidade e a fundamentação de quem julga, só resta a resistência civil e pacífica pelos prejudicados. 
Por fim, o ideal de justiça que deva prevalecer pressupõe a compreensão dos valores sociais, morais, éticos, políticos, econômicos, filosóficos, religiosos e jurídicos que todos expressem, mas que tragam progresso, evolução e sobretudo liberdade de pensar e de expressar esse pensamento pelos infindáveis meios da criatividade humana.

\section{REFERÊNCIAS}

ARENDT, Hannah. Origens do totalitarismo: Antissemitismo, imperialismo, totalitarismo. São Paulo: Companhia das Letras, 2012.

ARISTÓTELES. Política. São Paulo: Editora Martin Claret, 2001.

BOBBIO, Norberto. Política e cultura. São Paulo: Editora Unesp, 2015.

BURKE, Edmund. Reflexões sobre a Revolução na França. Campinas: Vide Editorial, 2017.

COURTOIS, Stéphane; WERTH, Nicolas; PANNÉ, Jean-Louis; PACZKOWSKI, Andrzej; BARTOSEK, Karel; MARGOLIN, Jean-Louis. O livro negro do

comunismo: Crimes, terror e repressão. Rio de Janeiro: Bertrand Brasil, 2019.

DWORKIN, Ronald. Uma questão de princípio. São Paulo: WMF Martins Fontes, 2019a.

DWORKIN, Ronald. O direito da liberdade. São Paulo: WMF Martins Fontes, 2019b.

FRIEDMAN, Milton. Capitalismo e liberdade. Rio de Janeiro: LTC, 2020.

HEGEL, Georg Wilhelm Friedrich. Princípios da filosofia do direito. São Paulo: WMF Martins Fontes, 1997.

HABERMAS, Jürgen. Facticidade e validade: contribuições para uma teoria discursiva do direito da democracia. São Paulo: Editora UNESP, 2020.

HABERMAS, Jürgen. A inclusão do outro: estudos de teoria política. São Paulo: Editora UNESP, 2018.

HAZONY, Yoram. A virtude do nacionalismo. Campinas: Vide Editorial, 2019. 
HIRSCHL, Ran. Rumo à juristocracia: As origens e consequências do novo constitucionalismo. Londrina: Editora EDA, 2020.

HUME, David. Tratado da natureza humana: uma tentativa de introduzir o método experimental de raciocínio nos assuntos morais. São Paulo: Editora UNESP, 2009.

KANT, Immanuel. Crítica da razão prática. Petrópolis: Editora Vozes, 2016.

KANT, Immanuel. Crítica da razão pura. Petrópolis: Editora Vozes, 2015.

KANT, Immanuel. Metafísica dos costumes. Petrópolis: Editora Vozes, 2013.

LEITE, Fábio Carvalho. Por uma posição preferencial do direito de resposta nos conflitos entre liberdade de imprensa e direito à honra. Revista eletrônica de Direito Civil, [S.I.], vol. 7, n. 1, 2018.

LOCKE, John. Ensaio sobre o entendimento humano. Lisboa: Fundação Calouste Gulbenkian, 1997a. vol. 1.

LOCKE, John. Ensaio sobre o entendimento humano. Lisboa: Fundação Calouste Gulbenkian, 1997b. vol. 2.

MALVESTIO, Rosangela Trabuco. Gênese das funções psíquicas: a formação do pensamento. Revista Educação Online, n. 20, p. 50-61, set./dez. 2015. Disponível em: http://educacaoonline.edu.puc-rio.br/index.php/eduonline/article/view/196.

Acesso em: 21 jan. 2021.

MAQUIAVEL, Nicolau. O Príncipe. São Paulo: Penguin Classics Companhia das Letras, 2010.

MARÍAS, Julián. História da filosofia. São Paulo: Martins Fontes, 2015.

MILL, John Stuart. Sobre a liberdade. Porto Alegre: L\&PM Pocket, 2019.

MILL, John Stuart. Considerações sobre o governo representativo. Porto Alegre: L\&PM Pocket, 2020.

MISES, Ludwig Von. Liberalismo. São Paulo: Instituto Ludwig von Mises, 2010.

PAINE, Thomas. Senso comum. São Paulo: Editora Martin Claret, 2005.

PLATÃO. A República. São Paulo: Editora Martin Claret, 2010.

RANIS, Gustav. Arthur Lewis' contribution to development thinking and policy. The Manchester School, New Haven, v. 72, n. 6, p. 712-723, dez. 2004. Disponível em: 
https://onlinelibrary.wiley.com/doi/abs/10.1111/j.1467-9957.2004.00431.x. Acesso em: 19 jan. 2021.

RAWLS, John. Uma teoria da justiça. São Paulo: Martins Fontes, 2016.

RIBEIRO, Djamila. O que é lugar de fala? Belo Horizonte: Letramento, 2017.

ROSS, Alf. Direito e justiça. Bauru: EDIPRO, 2007.

SANDEL, Michael. Justiça: O que é fazer a coisa certa. Rio de Janeiro: Civilização brasileira, 2012.

SANDEL, Michael. A tirania do mérito: O que aconteceu com o bem comum? Rio de Janeiro: Civilização brasileira, 2020.

SEN, Amartya. A ideia de justiça. São Paulo: Companhia das Letras, 2011.

SCRUTON, Roger. Conservadorismo: um convite à grande tradição. Rio de Janeiro: Record, 2019.

SMITH, Adam. Teoria dos sentimentos morais. São Paulo: Editora WMF Martins Fontes, 2015.

TOCQUEVILLE, Alexis de. Da democracia na América. Campinas: Vide Editorial, 2019.

VOLTAIRE. Dicionário filosófico. São Paulo: Editora Martin Claret, 2012.

VOLTAIRE. O preço da justiça. São Paulo: Editora Martins Fontes, 2006.

VOLTAIRE. Tratado sobre a tolerância: por ocasião da morte de Jean Calas. Porto Alegre: L\&PM, 2019.

WALZER, Michael. As esferas da justiça. Lisboa: Editorial Presença, 1999.

WEBER, Max. Ciência e política: duas vocações. São Paulo: Martin Claret, 2015.

WEINREB, Lloyd L. A razão jurídica: o uso da analogia no argumento jurídico. São Paulo: WMF Martins Fontes, 2008.

XAVIER, Dennys Garcia (org.). Thomas Sowell e a aniquilação de falácias ideológicas: breves lições. São Paulo: LVM Editora, 2019.

ZIMMERMANN, Ana Cristina; TORRIANI-PASIN, Camila. Filosofia e neurociência: entre certezas e dúvidas. Revista Brasileira de Educação Física e Esporte, São 
Paulo, v. 25, n. 4, p. 731-42, out./dez. 2011, p. 731. Disponível em:

https://www.scielo.br/pdf/rbefe/v25n4/v25n4a16. Acesso em: 21 jan. 2021. 